\title{
PENGARUH KOMPENSASI, LINGKUNGAN KERJA DAN FASILITAS SOSIAL TERHADAP KEPUASAN KERJA KARYAWAN KEBUN DI AFDELING 1 ESTATE TSB 1 PT. TRITUNGGAL SENTRA BUANA
}

\section{THE EFFECT OF COMPENSATION, WORK ENVIRONMENT AND SOCIAL FACILITIES ON JOB SATISFACTION OF PALM PLANTATION WORKERS IN AFDELING 1 ESTATE TSB 1 PT. TRITUNGGAL SENTRA BUANA}

\author{
Tantya Putri Andina1, Ernita Obeth ${ }^{1^{*}}$, Mujibu Rahman ${ }^{1}$ \\ ${ }^{1}$ Politeknik Pertanian Negeri Samarinda, Kampus Gunung Panjang, Jl. Samratulangi, \\ Samarinda, Indonesia \\ ${ }^{*}$ corresponding ernita.obeth@politanisamarinda.ac.id
}

\begin{abstract}
This research is motivated by factors that affect employee satisfaction at work such as compensation provided by the company, the work environment created around the company and social facilities available in the company. Therefore, the purpose of this study was to determine the effect of compensation, work environment and social facilities on employee job satisfaction. This study obtained data through filling out questionnaires and interviews with 27 respondents. Data were analyzed using multiple linear regression, are $T$ test to determine the effect of compensation, work environment, and social facilities partially on job satisfaction, $F$ test to determine the effect of compensation, work environment, and social facilities simultaneously on job satisfaction, and R2 test to determine the contribution off all independent variables (compensation, work environment, and social facilities) to the dependent variable (job satisfaction). The results of this study indicate that only compensation and work environment have a significant effect on job satisfaction. The compensation value ( $t$-count $2.67>t$-table 2.07) with a significance value of $0.013<0.05$ and the value of work environment ( $t$-count $3.52>t-$ table 2.07) with a significance value of $0.001<0,05$. The result of the $F$ test indicate that compensation, work environment, and social facilities have a significant effect on job satisfaction ( $F$-count $11.36>F$ table 3.03) with a significance value of $F 0.00009<0.05$. For the contribution or contribution of compensation, work environment and social facilities to job satisfaction, it shows a strong correlation with a percentage of 0.597 or $59.7 \%$.
\end{abstract}

Keywords: Compensation, Job Satisfaction, Social Facilities, Work Environment

\section{PENDAHULUAN}

Perkebunan merupakan salah satu subsektor pertanian yang berperan penting dalam pembangunan perekonomian di Indonesia. Dalam perkebunan, komoditas yang paling strategis dikembangkan adalah kelapa sawit. Hal ini dibuktikan oleh pentingnya peranan perkebunan kelapa sawit sebagai sumber perolehan devisa negara dalam sektor ekspor industri pengolahan minyak kelapa sawit. Pada tahun 2017, nilai ekspor minyak kelapa sawit mengalami peningkatan sebesar $27,40 \%$ dengan nilai US $\$ 20.340,9$ juta atau setara Rp 298 triliun (BPS, 2018).

Selain sebagai sumber perolehan devisa negara, perkebunan kelapa sawit juga dapat berperan dalam meningkatkan kesejahteraan masyarakat dengan menciptakan kesempatan kerja. Dalam menciptakan kesempatan kerja tentunya tidak terlepas dari sumber daya manusia (SDM). Di dalam perusahaan, sumber daya manusia merupakan individu yang bekerja pada perusahaan tersebut atau yang biasa disebut dengan karyawan. Perusahaan dan karyawan saling membutuhkan satu sama lain, dimana 
Andina, T.P, Obeth, E, dan Rahman, M. (2021) "Pengaruh Kompensasi, Lingkungan Kerja dan Fasilitas Sosial Terhadap Kepuasan Kerja Karyawan Kebun DI Afdeling 1 Estate TSB 1 PT. Tritunggal Sentra Buana", Jurnal Agriment, 6(2).

karyawan membutuhkan perusahaan agar dapat memenuhi kebutuhan hidupnya, sementara perusahaan membutuhkan karyawan yang berdedikasi tinggi dan produktif untuk meningkatkan kinerja perusahaan secara keseluruhan (Istijanto, 2006).

Salah satu upaya yang dapat dilakukan perusahaan untuk meningkatkan kinerja perusahaan adalah dengan mengusahakan kepuasan kerja bagi karyawan. Kepuasan kerja berkaitan dengan pemenuhan kebutuhan. Apabila karyawan sudah merasa terpenuhi kebutuhannya maka ia akan merasa puas atas pekerjaannya. Ini tampak dalam sikap positif dalam pekerjaan dan bertambahnya rasa kepuasan karyawan dalam bekerja.

\section{Bertambahnya rasa kepuasan} karyawan dalam bekerja tentunya ditunjang dengan berbagai faktor. Faktorfaktor yang mempengaruhi kepuasan karyawan dalam bekerja adalah kompensasi seperti gaji atau upah dan tunjangan-tunjangan yang diberikan oleh perusahaan, lingkungan kerja yang tercipta di sekitar perusahaan, dan fasilitas sosial yang tersedia di perusahaan.

Kepuasan kerja adalah suatu perasaan dalam diri tenaga kerja yang mendukung atau tidak mendukungnya dalam hal yang berhubungan dengan pekerjaannya. Perasaan yang berhubungan dengan pekerjaan tersebut meliputi aspek-aspek seperti gaji atau upah yang diterima, hubungan dengan tenaga kerja lainnya, penempatan kerja dan jenis-jenis perkerjaannya (Mangkunegara, 2009 dalam Darwis, 2019). Kompensasi merupakan bentuk penghargaan dan pembayaran oleh perusahaan kepada karyawannya yang muncul dari hasil pekerjaan mereka. Kompensasi meliputi dua komponen yaitu pembayaran langsung (berbentuk gaji, upah, insentif dan bonus) dan pembayaran tidak langsung (berbentuk tunjangan-tunjangan) (Dessler, 2009 dalam Nathania, 2016). Menurut Sedarmayanti, (2009) dalam Rahmawati, dkk (2014) lingkungan kerja merupakan keseluruhan dari alat perkakas dan bahan yang dijumpai, lingkungan sekitarnya dimana tempat seseorang bekerja, tata cara kerjanya, serta pengaturan pola kerjanya baik dalam bentuk kelompok maupun perorangan. Menurut Lupiyaodi (2006) dalam Nisa (2018), fasilitas merupakan sarana yang digunakan untuk memudahkan dan melancarkan dalam menjalankan fungsi.

Tujuan dilakukan penelitian ini adalah untuk dapat mengetahui pengaruh kompensasi, lingkungan kerja, dan fasilitas sosial terhadap kepuasan kerja karyawan di Afdeling 1 Estate TSB 1 PT. Tritunggal Sentra Buana.

\section{METODOLOGI}

\section{Metode Pengambilan Data}

Penelitian ini menggunakan kuesioner yang diadopsi dari Kamaruddin dkk (2016) untuk memperoleh data primer dari karyawan Afdeling 1 Estate TSB 1 Perusahaan Tritunggal Sentra Buana, Desa Saliki, Kecamatan Muara Badak, Kabupaten Kutai Kartanegara, Provinsi Kalimantan Timur. Selain menggunakan kuesioner, peneliti juga melakukan wawancara langsung terhadap responden untuk mengumpulkan dan memperoleh data primer. Data sekunder berkaitan dengan gambaran umum perusahaan, struktur organisasi dan data karyawan yang terkait dan mendukung dalam penelitian ini diperoleh dari pihak perusahaan.

\section{Metode Penentuan Sampel}

Dalam penelitian ini, peneliti menentukan sampel berdasarkan Arikunto (2010), jika populasinya kurang dari 100 orang sebaiknya diambil semuanya, jika populasi besar atau lebih besar dari 100 orang dapat diambil $10-15 \%$ atau $20-25 \%$. Jumlah karyawan di Afdeling 1 Esate TSB 1 berjumlah 143 orang, namun yang sesuai dengan batasan responden yaitu karyawan tetap laki-laki di kebun kelapa sawit yang memiliki usia muda (18-40 
tahun) dan sudah berkeluarga hanya berjumlah 27 orang. Karena total sampel jumlahnya kurang dari 100 orang maka seluruh karyawan yang sesuai dengan batasan responden diambil menjadi responden penelitian.

\section{Analisis Data}

Peneliti menggunakan analisis regresi linier berganda untuk mengetahui pengaruh antara satu variabel terikat dengan dua atau lebih variabel bebas. Maka model persamaan dan uji yang digunakan dalam penelitian ini adalah :

$$
\mathrm{Y}=\mathrm{a}+\mathrm{b}_{1} \mathrm{X}_{1}+\mathrm{b}_{2} \mathrm{X}_{2}+\mathrm{b}_{3} \mathrm{X}_{3}+\mathrm{e}
$$

Keterangan :

$\mathrm{a}=$ Konstanta

$\mathrm{b}=$ Koefisien regresi

$\mathrm{Y}=$ Variabel terikat yaitu Kepuasan Kerja Karyawan

$\mathrm{X}_{1}=$ Variabel bebas yaitu Kompensasi

$\mathrm{X}_{2}=$ Variabel bebas yaitu Lingkungan Kerja

$\mathrm{X}_{3}=$ Variabel bebas yaitu Fasilitas Sosial

$\mathrm{e}=$ Tingkat Kesalahan (error)

1. Uji t (Uji Parsial)

Uji $\mathrm{t}$ bertujuan untuk menguji signifikasi pengaruh masing- masing variabel bebas kompensasi $\left(X_{1}\right)$, lingkungan kerja $\left(X_{2}\right)$ dan fasilitas sosial $\left(X_{3}\right)$ mempunyai pengaruh yang signifikan terhadap variabel kepuasan kerja karyawan $(\mathrm{Y})$.

2. Uji F (Uji Simultan)

Uji $F$ bertujuan untuk menguji secara simultan (bersama-sama) pengaruh variabel bebas kompensasi $\left(X_{1}\right)$, lingkungan kerja $\left(X_{2}\right)$ dan fasilitas sosial $\left(X_{3}\right)$ terhadap variabel terikat kepuasan kerja karyawan $(\mathrm{Y})$.

3. Uji $R^{2}$ (Koefesien Determinasi)

Koefisien determinasi digunakan

untuk mengetahui kontribusi atau sumbangan dari variabel bebas yaitu kompensasi $\left(X_{1}\right)$, lingkungan kerja $\left(X_{2}\right)$ dan fasilitas sosial $\left(X_{3}\right)$ terhadap variabel terikat yaitu kepuasan kerja karyawan $(Y)$. Nilai koefisien determinasi adalah antara nol sampai satu $\left(0<R^{2}<1\right)$. Metodologi ditulis menggunakan Arial, 11 pt. rata kiri dan kanan, spasi tunggal. Di dalam metodologi berisikan metode penelitian yang dijelaskan secara rinci agar dapat diikuti oleh peneliti lainnya. Bagian ini harus dibuat sesingkat mungkin dengan mengacu pada prosedur yang telah dikeluarkan, kecuali jika metode yang digunakan di sini banyak dimodifikasi. Perlakuan, desain eksperimental, dan metode statistik harus dijelaskan secara rinci. Metode yang secara umum dikenal atau analisis dapat dijelaskan secara singkat dengan mengutip referensi yang relevan.

\section{HASIL DAN PEMBAHASAN}

\section{Identitas Responden}

Identitas responden digunakan untuk mengidentifikasi responden yang meliputi usia, jenis kelamin, tingkat pendidikan dan masa kerja yang dapat dilihat pada tabel-tabel yang diuraikan sebagai berikut :

a. Data Responden Berdasarkan Usia Karakteristik responden berdasarkan usia dapat dilihat pada Tabel 1 .

Tabel 1. Data Responden Berdasarkan Usia

\begin{tabular}{cccc} 
No. & Usia & Frekuensi & Presentase (\%) \\
\hline 1 & $24-26$ & 2 & $7 \%$ \\
2 & $27-29$ & 5 & $19 \%$ \\
3 & $30-32$ & 3 & $11 \%$ \\
4 & $33-35$ & 10 & $37 \%$ \\
5 & $36-38$ & 4 & $15 \%$ \\
6 & $39-41$ & 3 & $11 \%$ \\
\hline \multicolumn{2}{c}{ Jumlah } & 27 & $100 \%$ \\
\hline
\end{tabular}

Dari Tabel 1 dapat dilihat bahwa responden berdasarkan usia dalam penelitian ini, frekuensi paling tinggi berusia 33-35 tahun dengan presentase $37 \%$. Dengan demikian, dapat diketahui bahwa mayoritas usia para karyawan di Afdeling 1 Estate TSB 1 PT. Tritunggal Sentra Buana adalah berkisar antara 3335 tahun, dimana usia tersebut masih 
Andina, T.P, Obeth, E, dan Rahman, M. (2021) "Pengaruh Kompensasi, Lingkungan Kerja dan Fasilitas Sosial Terhadap Kepuasan Kerja Karyawan Kebun DI Afdeling 1 Estate TSB 1 PT. Tritunggal Sentra Buana", Jurnal Agriment, 6(2).

merupakan usia produktif. Hal ini sesuai dengan Suparmoko (2002), menyatakan bahwa perkerja yaitu orang yang berada pada usia kerja, pekerja pada usia kerja berkisar 15-64 tahun.

b. Data Responden Berdasarkan Tingkat Pendidikan

Karakteristik responden berdasarkan tingkat pendidikan dapat dilihat pada Tabel 2.

Tabel 2. Data Responden Berdasarkan Tingkat Pendidikan

\begin{tabular}{cccc}
\hline No. & Pendidikan & Frekuensi & $\begin{array}{c}\text { Presentase } \\
(\%)\end{array}$ \\
\hline 1 & SD & 10 & $37 \%$ \\
2 & SMP & 9 & $33 \%$ \\
3 & SMA $/ K$ & 8 & $30 \%$ \\
\hline \multicolumn{2}{r}{ Jumlah } & 27 & $100 \%$ \\
\hline
\end{tabular}

Berdasarkan Tabel 2, tingkat pendidikan dalam penelitian ini, frekuensi paling tinggi berada pada tingkat pendidikan SD sebanyak 10 orang dengan presentase $37 \%$, diikuti dengan tingkat pendidikan SMP sebanyak 9 orang dengan presentase 33\% dan yang paling sedikit adalah tingkat pendidikan SMA/K sebanyak 8 orang dengan presentase $30 \%$. Dari sisi tingkat pendidikan terakhir, diketahui presentase paling tinggi berada pada tingkat Sekolah Dasar (SD) sebesar $37 \%$. Hal tersebut dikarenakan para pekerja umumnya dari pedesaan yang sejak awal tidak mengikuti pendidikan formal ke jenjang yang lebih tinggi, hal lain ialah dikarenakan perusahaan perkebunan tidak terlalu menentukan syarat pendidikan yang tinggi sejalan dengan hasil Simamora (2012), yang mengemukakan bahwa tenaga kerja pemanen di perusahaan sebagian memiliki pendidikan rendah karena perusahaan tidak menetapkan tingkat pendidikan minimum yang tinggi dalam penerimaan tenaga kerja khusus lapangan. c. Data Responden Berdasarkan Masa

Kerja

Karakteristik responden berdasarkan masa kerja dapat dilihat pada Tabel 3

Tabel 3. Data Responden Berdasarkan Masa Kerja

\begin{tabular}{cccc}
\hline No. & Masa Kerja & Frekuensi & $\begin{array}{c}\text { Presentase } \\
(\%)\end{array}$ \\
\hline 1 & $1-2$ & 10 & $37 \%$ \\
2 & $3-4$ & 4 & $15 \%$ \\
3 & $5-6$ & 7 & $26 \%$ \\
4 & $7-8$ & 1 & $4 \%$ \\
5 & $9-10$ & 3 & $11 \%$ \\
6 & $11-12$ & 2 & $7 \%$ \\
\hline & Jumlah & 27 & $100 \%$ \\
\hline
\end{tabular}

Berdasarkan Tabel 3, masa kerja terlama pada responden yang diambil di Afdeling 1 Estate TSB 1 ialah berkisar 1-2 tahun sebanyak 10 orang dengan presentase $37 \%$ dari jumlah responden yang ditetapkan. Dengan demikian, maka sebagian besar karyawan di Afdeling 1 Estate TSB 1 tergolong baru bekerja di perusahaan. amun masa pengalaman kerja tersebut sudah cukup memadai untuk pekerja dapat melaksanakan pekerjaannya dengan baik. Hal ini berkaitan dengan penyataan Siswanto (2012), yang menyatakan bahwa semakin lama individu bekerja pada sebuah perusahaan maka individu tersebut akan semakin berpengalaman serta dapat memahami dan melaksanakan tugastugas pekerjaannya dengan baik.

2. Nilai Rata-rata Variabel

Nilai rata-rata variabel dapat dilihat pada Tabel 4. Dari Tabel 4, diketahui bahwa nilai rata-rata kepuasan kerja (Y) 3,5 yang berarti responden merasa puas. Nilai rata-rata kompensasi (X1) 3,3 yang berarti responden merasa cukup setuju dengan kompensasi yang ada. Nilai ratarata lingkungan kerja (X2) 1,9 yang berarti responden merasa kurang setuju dengan lingkungan kerja yang ada. Nilai rata-rata fasilitas sosial (X3) 3,6 yang berarti 
responden merasa setuju dengan fasilitas sosial yang ada.

Tabel 4. Nilai Rata-rata

\begin{tabular}{lc}
\hline \multicolumn{1}{c}{ Variabel } & Nilai Rata-rata \\
\hline Kepuasan Kerja (Y) & 3.5 \\
Kompensasi (X1) & 3.3 \\
Lingkungan Kerja (X2) & 1.9 \\
Fasilitas Sosial (X3) & 3.6 \\
\hline
\end{tabular}

\section{Analisis Regresi Linier Berganda}

Analisis regresi linier berganda digunakan untuk mengukur pengaruh kompensasi, lingkungan kerja dan fasilitas sosial terhadap kepuasan kerja karyawan yang dalam penelitian ini menggunakan program Microsoft Office Excel, sehingga didapatkan hasil mengenai model persamaan linear berganda dan uji analisis yang digunakan dalam penelitian ini.

Tabel 5. Hasil Analisis Regresi Linear Berganda

\begin{tabular}{lc}
\hline \multicolumn{1}{c}{ Variabel } & Coefficients \\
\hline Kepuasan Kerja $(\mathrm{Y})$ & 7.539527667 \\
Kompensasi $(\mathrm{X} 1)$ & 1.112527877 \\
Lingkungan Kerja & 1.346734142 \\
(X2) & 0.090708748 \\
\hline Fasilitas Sosial $(\mathrm{X} 3)$ & \\
\hline
\end{tabular}

\section{a. Koefisien Regresi Linier}

Berdasarkan Tabel 5 tersebut, persamaan regresi sebagai berikut :

$Y=a+b_{1} X_{1}+b_{2} X_{2}+b_{3} X_{3}$

$Y=7,53+1,11\left(X_{1}\right)+1,35\left(X_{2}\right)+0,09\left(X_{3}\right)$.

Hasil persamaan regresi linier berganda diperoleh :

$Y=7,53+1,11 X_{1}+1,35 X_{2}+0,09 X_{3}$

Hal ini menunjukkan nilai konstanta pada angka 7,53 jika variabel kompensasi, lingkungan kerja dan fasilitas sosial tidak mengalami perubahan maka kepuasan kerja memiliki angka 7,53. Jika koefisien kompensasi $\left(X_{1}\right)$ sebesar 1,11 ini menunjukan bahwa setiap peningkatan kompensasi sebesar 1 point, maka kepuasan kerja akan meningkat sebesar 1,11 dan sebaliknya. Jika koefisien lingkungan kerja $\left(X_{2}\right)$ sebesar 1,35 ini menunjukan bahwa setiap peningkatan lingkungan kerja sebesar 1 point, maka kepuasan kerja akan meningkat sebesar 1,35 dan sebaliknya. Jika koefisien fasilitas sosial $\left(X_{3}\right)$ sebesar 0,09 ini menunjukan bahwa setiap peningkatan fasilitas sosial sebesar 1 point, maka kepuasan kerja akan meningkat sebesar 0,09 dan sebaliknya.

\section{b. Uji t (Uji Parsial)}

Uji t dilakukan untuk mengetahui signifikasi pengaruh masing-masing variabel bebas kompensasi (X1), lingkungan kerja (X2) dan fasilitas sosial (X3) terhadap variabel terikat kepuasan kerja $(\mathrm{Y})$. Berikut adalah hasil uji t.

Pada Tabel 6 diketahui bahwa besarnya nilai t-hitung kompensasi $\left(X_{1}\right)$ sebesar 2,67 lebih besar dari pada t-tabel yaitu 2,07 dan nilai signifikansi 0,01363 masih berada di bawah 0,05 yang berarti kompensasi berpengaruh signifikan terhadap kepuasan kerja. Nilai t-hitung lingkungan kerja $\left(\mathrm{X}_{2}\right)$ sebesar 3,52 lebih besar dari pada t-tabel yaitu 2,07 dan dan nilai signifikansi 0,00184 masih berada di bawah 0,05 ini menunjukan bahwa lingkungan kerja berpengaruh signifikan terhadap kepuasan kerja. Nilai t-hitung fasilitas sosial $\left(X_{3}\right)$ sebesar 0,35 lebih kecil dari pada t-tabel yaitu 2,07 dan dan nilai signifikansi 0,73148 berada di atas nilai 0,05 yang berarti bahwa pengaruh fasilitas sosial terhadap kepuasan kerja tidak signifikan.

Nilai rata-rata kepuasan kerja untuk variabel kompensasi sebesar 3,3 ini berarti responden cukup sejutu dengan kompensasi yang diberikan perusahaan. Besarnya nilai t-hitung kompensasi $\left(X_{1}\right)$ 2,67 lebih besar dari nilai t-tabel 2,07 dengan nilai signifikansi $0,013<0,05$ ini menunjukkan bahwa kompensasi berpengaruh signifikan terhadap kepuasan kerja karyawan. Berdasarkan hasil dari wawancara dengan responden bahwa kompensasi yang diberikan oleh perusahaan dalam bentuk gaji/upah sebesar Rp.127.187/HK dengan HKE 
Andina, T.P, Obeth, E, dan Rahman, M. (2021) "Pengaruh Kompensasi, Lingkungan Kerja dan Fasilitas Sosial Terhadap Kepuasan Kerja Karyawan Kebun DI Afdeling 1 Estate TSB 1 PT. Tritunggal Sentra Buana", Jurnal Agriment, 6(2).

(Hari Kerja Efektif) 1 bulan yaitu 26 hari. Dengan demikian, besarnya gaji/upah yang diterima karyawan dalam 1 bulan sekitar Rp.3.306.862. Hal ini sesuai dengan UMK Kutai Kartanegara sebesar Rp.3.175.863. Besarnya gaji/upah yang diterima ini dapat mencukupi kebutuhan sehari-hari responden. Hasil ini sejalan dengan Prawira (2020), yang menemukan bahwa ada pengaruh positif dan signifikan dari kompensasi yang diberikan terhadap kepuasan kerja.

Tabel 6. Uji t

\begin{tabular}{lcccc}
\hline \multicolumn{1}{c}{ Variabel } & $t$ Stat & $t$ Tabel & P-value & Significance \\
\hline Kepuasan Kerja $(\mathrm{Y})$ & & & & \\
Kompensasi $(\mathrm{X} 1)$ & 2.67 & 2.07 & 0.01363 & 0.05 \\
Lingkungan Kerja $(\mathrm{X} 2)$ & 3.52 & 2.07 & 0.00184 & 0.05 \\
Fasilitas Sosial $(\mathrm{X} 3)$ & 0.35 & 2.07 & 0.73148 & 0.05 \\
\hline
\end{tabular}

Nilai rata-rata kepuasan kerja untuk variabel lingkungan kerja sebesar 1,9 ini berarti responden kurang sejutu dengan lingkungan kerja yang tercipta di sekitar perusahaan. Besarnya nilai t-hitung lingkungan kerja $\left(\mathrm{X}_{2}\right)$ sebesar 3,52 lebih besar dari nilai t-tabel 2,07 dengan nilai signifikansi $0,008<0,05$ ini menunjukkan bahwa lingkungan kerja berpengaruh signifikan terhadap kepuasan kerja karyawan. Berdasarkan hasil dari wawancara dengan responden bahwa lingkungan kerja yang tercipta di perusahaan masih dikatakan kotor dengan terdapatnya gulma yang banyak sehingga menyulitkan pekerja apabila bekerja di lingkungan kerja tersebut. Hasil penelitian ini sejalan dengan penelitian Darwis (2019) yang meneliti pengaruh lingkungan kerja dan beban kerja terhadap kepuasan kerja karyawan menemukan adanya pengaruh positif signifikan dari lingkungan kerja terhadap kepuasan kerja.

Nilai rata-rata kepuasan kerja untuk variabel fasilitas sosial sebesar 3,6 ini berarti responden cukup setuju dengan fasilitas sosial yang tersedia di perusahaan. Berdasarkan hasil dari wawancara dengan responden bahwa fasilitas sosial yang tersedia di perusahaan seperti transportasi gratis untuk anak ke sekolah tidak diperlukan karena sebagian responden merasa bisa mengantarkan dengan mudah anaknya ke sekolah menggunakan sepeda motor karena jarak antara sekolah dan tempat tinggal yang dekat. Perusahaan juga menyediakan fasilitas rekreasi seperti taman bermain untuk anak-anak karyawan, namun responden tidak merasa puas dengan tersedianya fasilitas tersebut karena taman bermain tersebut berada di kawasan berpagar atau di perusahaan kawasan tersebut bisa dikatakan sebagai kawasan untuk para Asisten Afdeling dan Manager Afdeling jadi para responden merasa tidak nyaman apabila hendak berjalan-jalan mengantarkan anaknya ke taman bermain tersebut. Besarnya nilai thitung fasilitas sosial $\left(X_{3}\right)$ sebesar 0,35 lebih kecil dari nilai t-tabel 2,07 dengan nilai signifikansi $0,731>0,05$ ini menunjukkan bahwa walaupun responden merasa ada beberapa fasilitas yang kurang, hal ini tidak mempengaruhi kualitas pekerjaan mereka.

c. Uji F (Uji Simultan)

Uji $F$ dilakukan untuk mengetahui secara simultan (bersama-sama) pengaruh variabel bebas kompensasi $\left(X_{1}\right)$, lingkungan kerja $\left(X_{2}\right)$ dan fasilitas sosial $\left(X_{3}\right)$ terhadap variabel terikat kepuasan kerja (Y). Berikut adalah hasil uji $F$

Dari Tabel 7 diketahui nilai Fhitung yaitu 11,36 lebih besar dari F-tabel yaitu 3,03 dan nilai signifikansi $F$ yang dihasilkan sebesar 0,00009 masih berada dibawah 0,05 ini menunjukkan bahwa terdapat pengaruh signifikan secara bersama-sama (simultan) antara variabel bebas kompensasi $\left(X_{1}\right)$, lingkungan kerja $\left(X_{2}\right)$ dan fasilitas sosial $\left(X_{3}\right)$ terhadap variabel terikat kepuasan kerja $(\mathrm{Y})$. 
Tabel 7 .Uji F

\begin{tabular}{lcccc}
\hline \multicolumn{5}{c}{ ANOVA } \\
\hline & $D f$ & $F$ & $F$ & Significance \\
tabel & $F$ \\
\hline Regression & 3 & 11.36 & 3.03 & $9.03341 \mathrm{E}-05$ \\
Residual & 23 & & & \\
Total & 26 & & & \\
\hline
\end{tabular}

d. Uji $R^{2}$ (Koefisien Determinasi)

Uji $R^{2}$ (koefisien determinasi) digunakan untuk mengetahui kontribusi atau sumbangan dari variabel bebas terhadap variabel terikat. Berikut adalah hasil uji $R^{2}$.

Tabel 8 .Uji R²(Koefisien Determinasi)

\begin{tabular}{lr}
\hline \multicolumn{2}{c}{ Regression Statistics } \\
\hline R Square & 0.597084074 \\
Standard Error & 3.337888741 \\
Observations & 27 \\
\hline
\end{tabular}

Tabel 8 menunjukkan bahwa kontribusi atau sumbangan dari variabel kompensasi $\left(X_{1}\right)$, lingkungan kerja $\left(X_{2}\right)$ dan fasilitas sosial $\left(X_{3}\right)$ terhadap kepuasan kerja $(Y)$ sebesar 0,597 atau 59,7\% sedangkan sisanya sebesar 40,3\% dipengaruhi oleh faktor lain diluar penelitian ini. Hal ini dapat diartikan bahwa $59,7 \%$ dari kepuasan kerja responden ditentukan oleh kompensasi, lingkungan kerja, dan fasilitas sosial, sedangkan sisanya sebesar $40,3 \%$ dipengaruhi oleh variabel lain yang tidak diteliti dalam penelitian ini. Maka disimpulkan bahwa antara variabel kompensasi, lingkungan kerja dan fasilitas sosial terhadap kepuasan kerja mempunyai hubungan yang kuat. Nilai koefisien determinasi yaitu antara nol dan satu. Berikut penjelasan mengenai nilai koefisien determinasi yaitu 0 (tidak ada kolerasi), 0-0,49 (kolerasi lemah), 0,50 (kolerasi moderat), 0,51-0,99 (korelasi kuat) dan 1 (kolerasi sempurna).

\section{KESIMPULAN}

Faktor kompensasi, lingkungan kerja dan fasilitas sosial berpengaruh terhadap kepuasan kerja, namun faktor yang berperngaruh secara signifikan hanya kompensasi dan lingkungan kerja. Nilai kontribusi dari ketiga faktor tersebut adalah hanya $59,7 \%$ selebihnya diduga oleh faktor lain.

\section{DAFTAR PUSTAKA}

Arikunto, S. 2010. Prosedur Penelitian Suatu Pendekatan Praktik. Rineka Cipta. Jakarta.

BPS. 2018. Analisa Komoditas Ekspor 2011-2017 Sektor Pertanian, Industri, dan Pertambangan. CV. Perdana Putra. Jakarta.

Darwis, R. 2019. Pengaruh Lingkungan Kerja dan Beban Kerja Terhadap Kepuasan Kerja Karyawan PT. Padasa Enam Utama Kalianta Satu Kabun Kabupaten Rokan Hulu. Skripsi. Universitas Islam Negeri Sultan Syarif Kasim. Pekan Baru.

Istijanto. 2006. Riset Sumber Daya Manusia. PT Gramedia Pustaka Utama. Jakarta.

Kamaruddin, R., M. Amizi, N. Abdullah, J. Ali, S.A. Ahmad. 2016. Job Satisfaction Among Malaysian Youth Working In The Oil Palm Plantation Sector: Analysis Of Attraction And Repulsion Factor. Jurnal Kuala Lumpur International Agriculture, Forestry and Plantation. Vol. 3:175176.

Nathania, C. 2016. Pengaruh Kompensasi Terhadap Kinerja Karyawan Pada PD Damai Motor Bandar Lampung. Skripsi Unvivertitas Lampung. Bandar Lampung.

Nisa, C. 2018. Pengaruh Fasilitas Kerja dan Lingkungan Kerja Terhadap Kinerja Karyawan PT. Indoking Aneka Agar-Agar Industri Medan.Skripsi Universitas Medan Area. Medan.

Prawira, I. 2020. Pengaruh Kompensasi, Kepemimpinan dan Fasilitas Kerja Terhadap Kepuasan Kerja Pegawai. Jurnal IImiah Magister Manajemen. Vol. 3, No. 1:28-40.

Rahmawati, N.P.,B. Swasto. dan A. Prasetya. $2014 . \quad$ "Pengaruh Lingkungan Kerja Terhadap Kinerja 
Andina, T.P, Obeth, E, dan Rahman, M. (2021) "Pengaruh Kompensasi, Lingkungan Kerja dan Fasilitas Sosial Terhadap Kepuasan Kerja Karyawan Kebun DI Afdeling 1 Estate TSB 1 PT. Tritunggal Sentra Buana", Jurnal Agriment, 6(2).

Karyawan Studi pada Karyawan Kantor Pelayanan Pajak Pratama Malang Utara". Jurnal Administrasi Bisnis. Vol. 8, No. 2:1-9.

Simamora, H. 2012. Manajemen Sumber Daya Manusia. Edisi 1. STIE YKPN Yogyakarta. Yogyakarta.

Siswanto, B. 2012. Manajemen Tenaga Kerja Indonesia:Pendekatan Administratif dan Operasional. Bumi Aksara. Jakarta.

Sofyan, S.H. 2001. Analisis Kritis Atas Laporan Keuangan. PT. Raja Grafindo. Jakarta.

Sugiyono. 2014. Metode Penelitian Kuantitatif Kualitatif dan R\&D. Alfabeta. Bandung.

Suparmoko. 2002. Ekonomi Publik untuk Keuangan dan Pembangunan Daerah. Andi. Yogyakarta 